\title{
Differences of patients' characteristics in acute type A aortic dissection - surgical data from Belgian and Japanese centers-
}

\author{
Motohiko Goda ${ }^{1,3^{*}}$, Tomoyuki Minami ${ }^{2}$, Kiyotaka Imoto ${ }^{2}$, Keiji Uchida ${ }^{2}$, Munetaka Masuda $^{3}$ and Bart Meuris ${ }^{1}$
}

\begin{abstract}
Background: It is well known that there are major differences between the Japanese and Western population regarding the incidence of ischemic heart disease and stroke. The purpose of this study was to evaluate differences of patients' characteristics between Belgian and Japanese cohort with acute type A aortic dissection.

Methods: In 487 patients (297 male patients, mean age 61.9 12.2 yrs) who underwent surgery for acute type A aortic dissection, baseline preoperative and intraoperative data were collected. Belgian patients $(n=237)$ were compared to Japanese patients $(n=250)$. Clinical data included patient demographics, history, status at presentation, imaging study results and intraoperative findings.

Results: The Japanese cohort had significantly more women (48.8\% vs. 28.7\%, $p<0.0001$ ), lower BMI (24.2 vs. 26.4, $p<0.0001)$ and lower prevalence of hypertension (49.2\% vs. 65.8\%, $p=0.0002)$. More DeBakey type I dissections and less type III dissections with retrograde extension were reported in Belgium than in Japan ( $77.2 \%$ vs. 48.4\%, $p<0.0001$, $3.4 \%$ vs. $38.7 \%, p<0.0001$, respectively). More entries were found in the ascending aorta (78.5\% vs. 58.5\%, $p<0.0001)$ and aortic arch (24.9\% vs. $13.7 \%, p=0.0018)$ in Belgian patients than in Japanese patients, who had more entries in the descending aorta or undetected entries.

Conclusions: In acute type A aortic dissection, Belgian patients reveal striking differences from Japanese patients regarding gender distribution, entry tear location and type of dissection. Japanese women are more likely to develop acute type A aortic dissection than Belgian women. (234 words).
\end{abstract}

Keywords: Acute aortic dissection, Epidemiology, Gender differences

\section{Background}

It is well known that the prevalence of ischemic heart disease and its mortality are significantly lower in Japan compared to the United States or to other Western populations [1-4]. On the contrary, Japanese people suffer significantly more from stroke, mainly the hemorrhagic type of stroke [1-4]. Within these two major cardiovascular disease types, there is a clear East/West divide [1]. Next to obvious and important differences in dietary habits (lower saturated fat and higher salt intake for the Japanese with subsequently much lower serum cholesterol levels), there might be genetic differences between

\footnotetext{
* Correspondence: gogomotto@gmail.com

${ }^{1}$ Department of Cardiac Surgery, University Hospitals Leuven, Leuven, Belgium

${ }^{3}$ Department of Cardiovascular Surgery, Yokohama City University Hospital,

Yokohama, Japan

Full list of author information is available at the end of the article
}

Japanese and Western people that underlie the observed differences in cardiovascular diseases [1-4]. But the actual causes for these differences in cardiovascular risk profile remain unknown and any explanation remains speculative. There is a higher prevalence of arterial hypertension within the general Japanese population, but this is insufficient to explain all phenomena. And although the Japanese dietary pattern has westernized these days, the trends in cardiovascular risk still last [4].

Acute type A aortic dissection (TA-AAD) is a life-threatening cardiovascular catastrophe which often requires emergency surgery to prevent death [5]. Within the International Registry of Acute Aortic Dissection (IRAD), geographic differences in clinical presentation, treatment and outcome in type A dissection have been studied, comparing European patients to North Americans. This study 
was able to reveal small differences in presentation and methods used for diagnosis, but overall these two Western patient cohorts were quite comparable [6]. Despite the known and described differences in ischemic heart disease and stroke between Asian and Western people, a comparison within patients with type A dissection has not been performed yet. The purpose of the present study is to evaluate differences in baseline patient characteristics and TA-AAD profile between Belgian and Japanese patient cohort.

\section{Methods}

\section{Study population}

We collected data from 487 patients (297 male; mean age $61.9 \pm 12.2$ y; range $14-88$ y) with TA-AAD who underwent emergency surgery at a Belgian center (University Hospital Leuven, Leuven, Belgium) or at a Japanese center (Yokohama City University Medical Center, Yokohama, Japan). Surgical interventions were performed in a time frame between January 1986 to September 2011 in the Belgian center and from January 2003 to December 2010 in the Japanese center. Diagnosis was made by imaging studies including computed tomography, magnetic resonance imaging and/or echocardiography. TA-AAD was defined as any dissection that involved the ascending aorta with presentation within 14 days of its onset. Approval by the local ethics committee was granted to collect and analyze patient data.

\section{Data collection}

Baseline clinical data on enrolled patients, including patient demographics, medical history, clinical findings at presentation, imaging study results, preoperative complications and intraoperative findings were collected and stored by retrospective chart review. Body mass index (BMI) was calculated (weight $(\mathrm{kg}) /$ height $\left.(\mathrm{m})^{2}\right)$.

\section{Literature and cardiac surgical society data}

In order to cross-check the baseline characteristics from our study cohort with current literature, a Pubmed search was performed for recent reports on TA-AAD within either Western centers (Europe, USA) or Eastern centers (Japan, Korea). Also, recent data on TA-AAD incidence from both the Belgian [6] and Japanese [7] cardiac surgical societies were used to estimate nationwide absolute incidence values.

\section{Statistical analysis}

All statistical analyses were performed using StatView J-5.0 (SAS Institute Inc., Cary, NC). Continuous variables were expressed as mean \pm standard deviation and were compared using the student's $t$ test. Categorical variables are expressed as absolute numbers or percentages and were compared using chi-square testing. The level of statistical significance was set at $p<0.05$.

\section{Results}

Demographics and patient history

Of the 487 patients enrolled in this study, 237 were from Belgium, and 250 were from Japan. All studied variables are listed in Tables 1 and 2. The proportion of women was significantly higher in Japan than in Belgium (48.8\% vs. $28.7 \%, p<0.0001)$. Belgian women were younger than Japanese women at the time of operation (61.2 vs. 67.6y, $p=0.0006$ ). Belgian patients had a higher BMI (26.4 vs. $24.2, p<0.0001$ ), they were taller (men; $1.76 \mathrm{~cm}$ vs. $1.68 \mathrm{~cm}, p<0.0001$, women; $1.64 \mathrm{~cm}$ vs. $1.54 \mathrm{~cm}$, $p<0.0001$ ), and heavier (men; $82.5 \mathrm{~kg}$ vs. $72.2 \mathrm{~kg}$, $p<0.0001$, women; $70.2 \mathrm{~kg}$ vs. $54.5 \mathrm{~kg}, p<0.0001)$ than Japanese patients.

Belgian patients had more preoperatively documented arterial hypertension ( $65.8 \%$ vs. $49.2 \%, p=0.0002)$, while in Japanese previously documented aortic aneurysms were more prevalent (59.6\% vs. $21.5 \%)$. Belgian patients had more previous cardiac operations $(6.3 \%$ vs. $1.6 \%$, $0.0071)$ than Japanese patients and there were more iatrogenic dissections $(1.7 \%$ vs. $0 \%, p=0.0391)$. There were no significant differences with regard to history of bicuspid aortic valve, Marfan syndrome, pregnancy, drug abuse or trauma.

Table 1 Demographics and patient history for Belgian and Japanese patients

\begin{tabular}{|c|c|c|c|}
\hline Variables & $\begin{array}{l}\text { Belgium } \\
(n=237)\end{array}$ & $\begin{array}{l}\text { Japan } \\
(n=250)\end{array}$ & $p$ Value \\
\hline Gender (Men/Women) & $169 / 68$ & $128 / 122$ & $<0.0001$ \\
\hline Age (yrs) & $59.3 \pm 12.7$ & $63.3 \pm 11.3$ & $<0.0001$ \\
\hline Age $<40$ yrs & $13(5.5 \%)$ & $5(2 \%)$ & 0.0416 \\
\hline Age $\geq 80$ yrs & $10(4.2 \%)$ & $19(7.6 \%)$ & 0.1151 \\
\hline Body Mass Index & $26.4 \pm 4.1$ & $24.2 \pm 3.7$ & $<0.0001$ \\
\hline Hypertension & $156(65.8 \%)$ & $123(49.2 \%)$ & 0.0002 \\
\hline Known aortic aneurysm ( $\geq 4 \mathrm{~cm})$ & $51(21.5 \%)$ & $149(59.6 \%)$ & $<0.0001$ \\
\hline Bicuspid aortic valve & $5(2.1 \%)$ & $1(0.4 \%)$ & 0.1008 \\
\hline Marfan syndrome & $7(3 \%)$ & $7(2.8 \%)$ & 0.9192 \\
\hline Other connective tissue disease & $2(0.8 \%)$ & $0(0 \%)$ & 0.1455 \\
\hline Pregnant & $2(0.8 \%)$ & $0(0 \%)$ & 0.1455 \\
\hline Drug & $2(0.8 \%)$ & $0(0 \%)$ & 0.1455 \\
\hline Trauma & $1(0.4 \%)$ & $0(0 \%)$ & 0.3039 \\
\hline latrogenic & $4(1.7 \%)$ & $0(0 \%)$ & 0.0391 \\
\hline Previous cardiac operation & $15(6.3 \%)$ & $4(1.6 \%)$ & 0.0071 \\
\hline $\begin{array}{l}\text { Post cardiac operation } \\
\text { within hospital stay }\end{array}$ & $3(1.3 \%)$ & $0(0 \%)$ & 0.0744 \\
\hline $\begin{array}{l}\text { Post cardiac operation } \\
\text { within } 2 \text { years }\end{array}$ & $13(5.5 \%)$ & $1(0.4 \%)$ & 0.0008 \\
\hline
\end{tabular}


Table 2 Demographics by gender

\begin{tabular}{llll}
\hline Variables & Belgium & Japan & $p$ Value \\
\hline Men & $n=169$ & $n=128$ & \\
Age (yrs) & $58.6 \pm 11.8$ & $61.1 \pm 11.1$ & 0.0607 \\
Age $<40$ yrs & $8(4.7 \%)$ & $3(2.3 \%)$ & 0.2801 \\
Age $\geq 80$ yrs & $6(3.6 \%)$ & $5(3.9 \%)$ & 0.8722 \\
Length (m) & $1.75 \pm 0.07$ & $1.68 \pm 0.06$ & $<0.0001$ \\
Weight (kg) & $82.5 \pm 14.1$ & $72.2 \pm 11$ & $<0.0001$ \\
Body Mass Index & $26.5 \pm 3.9$ & $25.5 \pm 3.4$ & 0.0166 \\
Hypertension & $107(63.3 \%)$ & $62(48.4 \%)$ & 0.0104 \\
Women & $n=68$ & $n=122$ & \\
Age (yrs) & $61.2 \pm 14.5$ & $67.6 \pm 10.5$ & 0.0006 \\
Age $<40$ yrs & $5(7.4 \%)$ & $2(1.6 \%)$ & 0.0045 \\
Age $\geq 80$ yrs & $4(5.9 \%)$ & $14(11.5 \%)$ & 0.2059 \\
Length (m) & $1.64 \pm 0.08$ & $1.54 \pm 0.07$ & $<0.0001$ \\
Weight (kg) & $70.2 \pm 13.6$ & $54.5 \pm 10.5$ & $<0.0001$ \\
Body Mass Index & $26.5 \pm 3.9$ & $25.5 \pm 3.4$ & $<0.0001$ \\
Hypertension & $49(72.1 \%)$ & $61(50 \%)$ & 0.0082 \\
\hline
\end{tabular}

Type of aortic dissection and preoperative complications

Table 3 shows that DeBakey type I dissections were more frequent in Belgium (77.2\% vs. $48.4 \%, p<0.0001$ ) while Type III dissections with retrograde extension were less frequent in Belgium than in Japan (3.4\% vs. $38.7 \%, p<0.0001)$. More entries were found in the ascending aorta $(78.5 \%$ vs. $58.5 \%, p<0.0001)$ and aortic arch $(24.9 \%$ vs. $13.7 \%, p=0.0018)$ in Belgian patients than in Japanese patients.

Shock was more frequent in Belgian patients than in Japanese patients ( $28.3 \%$ vs. $18.8 \%, p=0.0136)$, however, cardiac tamponade was more frequent in Japan than in Belgium (29.6\% vs. $17.3 \%, p=0.0014)$. As to complications associated with impaired arterial blood flow, the prevalence of renal ischemia $(5.5 \%$ vs. $1.2 \% . p=0.008)$ and paraparesis/paraplegia (3.8\% vs. $0.8 \%, p=0.0261)$ were more frequent in Belgium than in Japan. There were no significant differences with regard to development of stroke, myocardial ischemia, mesenteric ischemia, and limb ischemia.

\section{Discussion}

The occurrence of cardiovascular diseases is certainly associated with genetic factors, life style, dietary factors, environmental conditions and coexisting diseases. Therefore, it is reasonable that there are regional differences in incidence and mortality of different cardiovascular pathologies. The fact that Japan has less ischemic heart disease and more hemorrhagic stroke has been epidemiologically studied and is well recognized these days $[1-4,8,9]$. In the present study we highlight that also acute type A dissection is a disease with regional
Table 3 Type of aortic dissection and complications for Belgium and Japanese patients

\begin{tabular}{llll}
\hline Variables & $\begin{array}{l}\text { Belgium } \\
(n=237)\end{array}$ & $\begin{array}{l}\text { Japan } \\
(n=250)\end{array}$ & $p$ Value \\
\hline DeBakey I & $183(77.2 \%)$ & $121(48.4 \%)$ & $<0.0001$ \\
DeBakey II & $43(18.1 \%)$ & $31(12.4 \%)$ & 0.084 \\
Stanford type B with & $8(3.4 \%)$ & $96(38.4 \%)$ & $<0.0001$ \\
retrograde extension & & & \\
Entry & $186(78.5 \%)$ & $145(58 \%)$ & $<0.0001$ \\
$\quad$ Ascending aorta & $59(24.9 \%)$ & $34(13.6 \%)$ & 0.0018 \\
$\quad$ Aortic arch & $8(3.4 \%)$ & $25(10 \%)$ & 0.0084 \\
$\quad$ Descending aorta & $0(0 \%)$ & $44(17.6 \%)$ & $<0.0001$ \\
$\quad$ Not found & $67(28.3 \%)$ & $47(18.8 \%)$ & 0.0136 \\
Shock & $41(17.3 \%)$ & $74(29.6 \%)$ & 0.0014 \\
Cardiac tamponade & $6(2.5 \%)$ & $14(5.6 \%)$ & 0.0881 \\
Cardiopulmonary resuscitation & $16(6.8 \%)$ & $16(6.4 \%)$ & 0.8758 \\
Stroke & $9(3.8 \%)$ & $2(0.8 \%)$ & 0.0261 \\
Paraparesis/paraplegia & $27(11.4 \%)$ & $30(12 \%)$ & 0.8349 \\
Lower limb ischemia & $13(5.5 \%)$ & $3(1.2 \%)$ & 0.008 \\
Renal ischemia & $4(1.7 \%)$ & $9(3.6 \%)$ & 0.1907 \\
Mesenteric ischemia & $15(6.3 \%)$ & $13(5.2 \%)$ & 0.5926 \\
Myocardial ischemia & & & \\
\hline
\end{tabular}

differences in patient characteristics when Belgian and Japanese patient cohort are compared.

The larger proportion of women in Japanese TA-AAD patients is a remarkable demographic finding in this study. Based on reports from predominantly Western centers, the gender distribution in TA-AAD has always been described as a 2:1 male:female ratio [10-12]. This 2:1 male/female ratio is frequently reported by IRAD and can be found in many textbooks of cardiac surgery $[13,14]$. But does this ratio hold true for the Eastern population? The Japanese series in this study showed $48.8 \%$ female patients (who were also significantly older). Other reports from Japanese centers (with at least 80 surgical TA-AAD cases) also reported as many as 39.1 to $58.8 \%$ of female patients [15-20]. Similarly, recent reports from Korea [21-24] described proportions of female patients up to 42.4 to $52.7 \%$, very similar to the reports from Japan. Therefore, it seems that within the East-Asian population, the gender distribution male:female in TA-AAD patients is more a 1:1 ratio, or Asian women are more likely to develop TA-AAD compared to Western women. According to the organization for economic co-operation and development (OECD) [25], the number of annual deaths from circulatory system diseases in Japanese women was 380 per 1,000,000 persons per year, which is much less than the 940 deaths per million per year in Belgian women. With a significantly lower overall death from cardiovascular diseases, 
it is paradoxical that Japanese women are more likely to develop TA-AAD, but the etiology behind it might be similar to that causing the higher numbers of hemorrhagic stroke in Japanese women [4]. One can hypothesize that Japanese woman have a more pronounced vessel wall fragility.

The detected differences in the incidence of arterial hypertension are paradoxical, because Japanese have a higher nationwide prevalence of hypertension [25]. Also the fact that more Japanese had previously documented aneurysms is enigmatic. The remaining observed differences in number of redo cases, iatrogenic cases, occurrence of malperfusion and tamponade should be interpreted with caution, given the relatively low number of observations.

It is impossible to investigate the absolute incidence or prevalence of acute aortic dissection. Reported incidences may underestimate the 'real' population value, because TA-AAD also causes sudden death before any diagnostic investigation has been performed. Textbooks teach us an 'estimated worldwide incidence' of 5 to 29.5 per 1,000,000 per year [26]. But also figures between 29 to 52 per $1,000,000$ per year have been reported [27-30]. It is important to know that some of these values originate from observations of relatively small patient cohorts and are then extrapolated to the general population of a country. Current data from two Western cardiac surgical societies and registries teach us the following incidences per 1,000,000 persons per year: Belgium 8.1 [7]. The IRAD registry reports an annual incidence of 4.1 per million and data from the USA show an estimated incidence of 2 to 8 per million per year [26]. Surprisingly, Japan reports 27.2 operated TA-AAD cases per million persons in 1 year [31], which is 4 to 7 times higher compared to the current Western data. It seems that the worldwide incidence of acute aortic dissections is indeed - like the textbooks show - within a range 5 to 30 per million per year, but that the incidence in Western people is more on the lower side of this spectrum while Japanese people are on the higher side.

Within TA-AAD patients, type I dissections are the predominant form (in Western series), and in up to 60$68 \%$ of cases, the location of the entry tear is within the ascending aorta $[13,14,26]$. Our observation confirmed this pattern and the main entry tear location. But the Japanese data show a different pattern: fewer entries were found in the ascending aorta and more retrograde dissections extending from the descending aorta were observed. Also in a high proportion of patients, no entry tear was found at all, suggesting a tear in the lower descending aorta. The retrograde extension of aortic dissection leads patients with type B dissection to type A. This may partly explain the higher number of TA-AAD cases in Japan compared to other western countries.
Both more prevalent of documented aortic aneurysm and the retrograde extension of aortic dissection are possibly attributed to a vessel fragility of Japanese people. The reason why there would be higher vessel fragility in Japanese remains unknown. Hypotheses have been provided linking low serum cholesterol levels to altered mechanical properties of endothelium and vessel wall quality. Further investigation with comparison of biomechanical characteristics of tissue within both populations is needed to elaborate our findings further.

\section{Conclusion}

Belgian patients with TA-AAD differ from Japanese patients with respect to gender, entry tear location and type of dissection. The absolute incidence of TA-AAD in Japan is higher. Especially Japanese women are more likely to develop TA-AAD than Belgian women.

\section{Study limitations}

This study included single center data from each country and the numbers of the subjects are relatively small. Only patient data with TA-AAD were evaluated in this study, medically treated cases, chronic dissections or type B dissection data was not included. Pre- and intraoperative factors alone were gathered and studied, without outcome data. The study periods were different between the two centers. No pathological or biomechanical investigations were performed.

\section{Abbreviations}

BMI: Body mass index; IRAD: The International Registry of Acute Aortic Dissection; OECD: the organization for economic co-operation and development; TA-AAD: Acute type A aortic dissection

\section{Availability of data and materials}

The dataset analyzed during the current study are available from the corresponding author on reasonable request.

\section{Authors' contributions}

Concept/design: MG, BM, Data collection: MG, TM, KU, BM, Data analysis/ interpretation: $M G$, Drafting article: $M G$, Critical revision of the article: $M G, K U$, MM, Approval of the article: BM. All authors read and approved the final manuscript.

\section{Ethics approval and consent to participate}

This retrospective cohort study was performed at two centers in human subjects and was reviewed and approved by the Institutional Review Board at University Hospitals Leuven and Yokohama City University Medical Center. Informed consent for this study was waived because no individual patients were identified.

\section{Consent for publication}

Not applicable.

Competing interests

The authors declare that they have no competing interests.

\section{Publisher's Note}

Springer Nature remains neutral with regard to jurisdictional claims in published maps and institutional affiliations. 


\section{Author details}

'Department of Cardiac Surgery, University Hospitals Leuven, Leuven, Belgium ${ }^{2}$ Cardiovascular Center, Yokohama City University Medical Center, Yokohama, Japan. ${ }^{3}$ Department of Cardiovascular Surgery, Yokohama City University Hospital, Yokohama, Japan.

Received: 22 May 2018 Accepted: 29 August 2018

Published online: 04 September 2018

\section{References}

1. Kita T. Coronary heart disease risk in Japan - an east/west divide? Eur Heart J Suppl. 2004;6:A8-A11.

2. Ueshima $\mathrm{H}$. Explanation for Japanese paradox: prevention of increase in coronary heart disease and reduction in stroke. J Atheroscler Thromb. 2007; 14:278-86.

3. Ueshima H, Sekikawa A, Miura K, Turin TC, Takashima N, Kita Y, Watanabe M, Kadota A, Okuda N, Kadowaki T, Nakamura Y, Okamura T. Cardiovascular disease and risk factors in Asia: a selected review. Circulation. 2008;118: 2702-9.

4. Shinohara Y. Regional differences in incidence and management of stroke-is there any difference between western and Japanese guidelines and antiplatelet therapy? Cerecrovasc Dis. 2006;21:17-24.

5. Goda M, Imoto K, Suzuki S, Uchida K, Yanagi H, Yasuda S, Masuda M. Risk analysis for hospital mortality in patients with acute type a aortic dissection. Ann Thorac Surg. 2010;90:1246-50.

6. Raghupathy A, Nienaber CA, Harris KM, Myrmel T, Fattori R, Sechtem U, Oh J, Trimarchi S, Cooper JV, Booher A, Eagle K, Isselbacher E, Bossone E. Geographic differences in clinical presentation, treatment, and outcome in acute type a aortic dissection (from the international registry of acute aortic dissection). Am J Cardiol. 2008;102:1562-6.

7. Report on the demographics, management and outcome of the surgical treatment for acute type A aortic dissection. A prospective study in Belgian cardiac surgical centers over a one-year period (2008-2009) with a one-year follow-up. Available at http://www.bacts.org/documents/PDF/Database/ typeAreport.pdf. Accessed 31 Aug 2018

8. Ueshima H, Okayama A, Saitoh S, Nakagawa H, Rodrigues B, Sakata K, Okuda N, Choudhury SR, Curb JD, for the INTERLIPID Resaech group. Differences in cardiovascular disease risk factors between Japanese in Japan and Japanese-Americans in Hawaii: the INTERLIPID study. J Hum Hypertens. 2003;17:631-9.

9. Nakamura H, Arakawa K, Itakura H, Kitabatake A, Goto Y, Toyota T, Nakaya N, Nishimoto S, Muranaka M, Yamamoto A, Muzuno K, Ohashi Y, for the MEGA Study Group. Primary prevention of cardiovascular disease with pravastatin in Japan (MEGA study): a prospective randomised controlled trial. Lancet. 2006;368:1155-63.

10. Nienaber CA, Fattori R, Mehta RH, Richartz BM, Evangelista A, Petzsch M, Cooper JV, Januzzi JL, Ince H, Sechtem U, Bossone E, Jianming F, Smith DE, Isselbacher EM, Pape LA, Eagle KA. Gender-related differences in acute aortic dissection. Circulation. 2004;109:3014-21.

11. LeMaire SA, Russell L. Epidemiology of thoracic aortic dissection. Nat Rev Cardiol. 2011:8:103-13.

12. Tsai $\Pi$, Trimarchi S, Nienaber CA. Acute aortic dissection: perspectives from the international Registory of acute aortic dissection (IRAD). Eur J Vasc Endovasc Surg. 2009;37:149-59.

13. Reece TB, Green GR, Kron IL. Aortic dissection. In: Cohn LH, editor. Cardiac surgery in the adult. 3rd ed. New York: McGraw-Hill; 2003. p. 53-84.

14. Eang DS, Kake MD. Endovacular therapy for aortic Disection. In Rousseau H, Verhoye JP, Heautor JF. Thoracic aortic diseases. New York: Springer Berlin Heidelberg; 2006. p. 189-97.

15. Uchida N, Shibamura H, Katayama A, Shimada N, Sutoh M, Ishihara H. Operative strategy for acute type a aortic dissection: ascending aortic or hemiarch versus total arch replacement with frozen elephant trunk. Ann Thorac Surg. 2009;87:773-7.

16. Tanaka M, Kimura N, Yamaguchi A, Adachi H. In-hospital and long term results of surgery for acute type a aortic dissection: 243 consecutive patients. Ann Thorac Cardiovasc Surg. 2012;18:18-23.

17. Yamanaka K, Hori Y, Ikarashi J, Kusuhara T, Nakastuka D, Hirose K, Nishina F, Fujita M. Durability of aortic valve prevervartion with root reconstruction for acute type a aortic dissection. Eur J Cardiothorac Surg. 2012;41(4):e32-36.

18. Hata M, Suzuki M, Sezai A, Niino T, Yoshitake I, Unosawa S, Shimamura K, Minami K. Outcome of less invasive proximal arch replacement with moderate hypothermic circulatory arrest followed by aggressive rapid rewarming in emergency surgery for acute type a aortic dissection. Circ J. 2009;73:69-72.

19. Minatoya K, Ogino H, Matsuda H, Sasaki K. Rapid and safe establishment of cardiopulmonary bypass in repair of acute aortic dissection: improved results with double cannulation. Interact Cardiovasc Thorac Surg. 2008;7: 951-3.

20. Kazui T, Yamashita K, Washiyama N, Terada H, Bashar AH, SuzukiT OK. Impact of an aggressive surgical approach on surgical outcome in type a aortic dissection. Ann Thorac Surg. 2002;74:S1844-7.

21. Song JK, Yim JH, Ahn JM, Kim DH, Kang JW, Lee YT, Song JM, Choo SK, Kang DH, Chung CH, Lee JW, Lim TH. Outcome of patients with acute type a aortic intramural hematoma. Circulation. 2009;120:2046-52.

22. Ryu HM, Lee JH, Kwon SY, Park SH, Lee SH, Bae MH, Lee JH, Yang DH, Park HS, Cho Y, Chae SC, Jun JE, Park WH. Examing the relationship between triggering activities and the circadian distribution of acute aortic dissection. Korean Circ J. 2010;40:565-72.

23. Kim JB, Chung CH, Moon DH, Ha GJ, Lee TY, Jung SH, Choo SJ, Lee JW. Total arch repair versus hemiarch repair in the management of acute DeBakey type I aortic dissection. Eur J Cardiothorac Surg. 2011;40:881-7.

24. Kim EK, Choi ER, Ko SM, Jang SY, Choi SH, Ki CS, Choe YH, Kim WS, Sung K, Oh JK, Kim DK. Comparison of aortic dissection in Korean patients with versus without the marfan syndrome. Am J Cardiol. 2012;109:423-7.

25. OECD. Society at a Glance 2011 - OECD Social Indicators. 2011. Available at: https://www.oecd-ilibrary.org/social-issues-migration-health/society-at-aglance-16. Accessed 31 Aug 2018.

26. Coady MA, Rizzo JA, Goldstein LJ, Elefterades JA. Natural history, pathogenesis, and etiology of thoracic aortic aneurysm and dissections. Cardiol Clin. 1999;17:615-35.

27. Meszaros I, Morocz J, Szlavi J, Schmidt J, Tornoci L, Nagy L, Szep L. Epidemiology and clinicopathology of aortic dissection: a population-based longitudinal study over 27 years. Chest. 2000;117:1271-8.

28. Clouse WD, Hallett JW Jr, Schaff HV, Spittel PC, Rowland CM, Ilstrup DM, Melton $\sqcup$ 3rd. Acute aortic dissection: population-based incidence compared with degenerative aortic aneurysm rupture. Mayo Clin Proc. 2004 79:176-80.

29. Guidelines for Diagnosis and Treatment of Aortic Aneurysm and Aortic Dissection (JCS 2006). J Cardiol. 2007;50:547-77.

30. Yu HY, Chen YS, Huang SC, Wang SS, Lin FY. Late outcome of patients with aortic dissection: study of a national database. Eur J Cardiothoracic Surg. 2004:25:683-90

31. Sakata R, Fujii $Y$, Kuwano $H$. Thoacic and cardiovascular surgery in Japan during 2009. Gen Thorac Cardiovasc Surg. 2011;59:636-67.

Ready to submit your research? Choose BMC and benefit from:

- fast, convenient online submission

- thorough peer review by experienced researchers in your field

- rapid publication on acceptance

- support for research data, including large and complex data types

- gold Open Access which fosters wider collaboration and increased citations

- maximum visibility for your research: over $100 \mathrm{M}$ website views per year

At BMC, research is always in progress.

Learn more biomedcentral.com/submissions 